\title{
Inverting Instruction in a Semiconductor Devices Course: A Case Study of a Flipped Electrical Engineering Classroom
}

\section{Vignesh Subbian, University of Cincinnati}

Vignesh Subbian is an instructor in the Department of Electrical Engineering and Computing Systems at the University of Cincinnati. His research interests include biomedical devices and informatics, humancomputer interaction, and engineering education.

\section{Dr. Gregory Warren Bucks, University of Cincinnati}

Gregory Bucks joined the Department of Engineering Education in 2012. He received his BSEE from the Pennsylvania State University in 2004, his MSECE from Purdue University in 2006, and his PhD in Engineering Education in 2010, also from Purdue University. After completing his $\mathrm{PhD}$, he taught for two years at Ohio Northern University in the Electrical and Computer Engineering and Computer Science department, before making the transition to the University of Cincinnati. He has taught a variety of classes ranging introductory programming and first-year engineering design courses to introductory and advanced courses in electronic circuits. He is a member of ASEE, IEEE, and ACM.

\section{Dr. Jason C Heikenfeld, University of Cincinnati}

Dr. Jason Heikenfeld is an internationally-known leading scientist in electrofluidic device research for biosensors, beam steering, lab-on-chip, displays, and electronic paper. He is an NSF CAREER, AFOSR and Sigma Xi Young Investigator. Dr. Heikenfeld is a Senior member of the Institute for Electrical and Electronics Engineers, a Senior member of the Society for Information Display, and a member of SPIE, a member of ASEE, and a Fellow of the National Academy of Inventors. In addition to his scholarly work, Dr. Heikenfeld is now launching his 3rd startup company, and has lead the creation of programs and coursework at the University of Cincinnati that foster innovation, entrepreneurship, and an understanding of the profound change that technology can have on society. Website: http://www.ece.uc.edu/devices/ 


\title{
Inverting Instruction in a Semiconductor Devices Course: A Case Study of a Flipped Electrical Engineering Classroom
}

\begin{abstract}
In this paper, we report our experiences in implementing a flipped classroom model in a semiconductor devices course. The paper presents the course design, pedagogical methods, and results from the most recent offering of the course (Fall 2014). The course design and implementation provide simple solutions to effectively transform and offer a flipped engineering course. Furthermore, to emphasize the need for strategic approaches to implement a flipped/blended learning environment, we include (1) a teaching "toolbox" for flipped pedagogy and (2) recommendations for creating awareness of blended learning at the institution-level.
\end{abstract}

\section{Introduction}

Blended Learning (BL) may refer to the combination of different instructional modalities, methods, or media ${ }^{1}$. An evolving definition of BL is combining aspects of traditional face-toface (F2F) and online instruction in a formal academic setting ${ }^{2}$. The scope, content, and learning achieved through each modality (F2F or online), however, varies significantly across institutions and educators ${ }^{3}$. A flipped (inverted) pedagogical model promotes BL by moving the lecture content outside the classroom (through online videos and reading) and bringing active learning and problem-solving inside the classroom. More specifically, a typical flipped classroom allows for higher-order learning (analysis, evaluation, and synthesis) through active and collaborative work during class time, and provides the necessary lower-level content through online videos and reading prior to class ${ }^{4}$. Research literature supports that flipped classrooms allow instructors to dedicate more in-class time to observing student performance, identifying misconceptions, and providing personalized and immediate feedback to individual or groups of students ${ }^{4-6}$. A recent survey of research on flipped classrooms ${ }^{7}$ showed that the implementation details of both inclass and out-of-activities are often unclear in research studies. Additionally, the logistics of these activities differ considerably across and within disciplines, including electrical and computer engineering curricula. Drawing upon these limitations, we present a case study of a flipped electrical engineering classroom in an urban research university.

\section{Background}

EECE 2077 - Semiconductor Devices is a 3-credit hour required course for all undergraduate electrical engineering majors at the University of Cincinnati (UC). The course content can be classified into four broad topics: Diodes, Bipolar Junction Transistors (BJTs), Field Effect Transistors (FETs), and Optoelectronics.

The ABET learning outcomes of the course are as follows:

1. Comprehend the basic electrical and chemical concepts that govern semiconductor junctions with another semiconductor, a metal, or an oxide and a metal. (a) 
2. Apply knowledge of junction-based and field-effect transistors. (a)

3. Synthesize transistor function through utilization of a corresponding simple circuit model. (e)

4. Use computing tools to plot transistor electrical characteristics. $(\mathrm{k})$

Until 2012, this course was offered in a traditional in-class lecture format. In Fall 2013, the course was transformed and offered in a flipped classroom model. In this paper, we focus on a teaching toolbox, including the logistics of in-class activities and strategic approaches for flipped pedagogy adoption, based on our experiences in the most recent offering of the course in Fall 2014.

\section{A teaching toolbox for flipped pedagogy}

We present the course design as a teaching toolbox for flipped pedagogy to help readers and instructors easily gather and use BL-related recommendations and templates as needed. The overall goal of the Semiconductor Devices course is for each student to examine and understand the operation of semiconductor devices and the processes underlying their operation. The course delivery includes three major components: (1) out-of-class online video lectures, (2) in-class activities (mini-quiz, lecture review, and group problem-solving, and (3) four in-class tests.

\section{Developing Video Lectures (out-of-class activities)}

Videos of the lecture content are assigned to be watched outside the classroom. Students are given a minimum of 2 days to watch the lectures before coming to class. There are several commercial and open-source software applications that can be used to record videos. We used the Explain Everything app for developing video lectures. It is an easy-to-use application that allows creation of learning modules with narration, animation, and annotation. It is available for Windows, iOS and Android platforms.

\section{Developing in-class activities}

The EECE 2077 class meets for 80 minutes, twice per week. The in-class activities consists of three learning activities: (1) quiz (2 minutes), (2) review of online/video lectures (5-10 minutes), and (3) group problem-solving (70 - 75 minutes).

1) Quiz (2 minutes): Each class starts with a brief quiz with 2-3 multiple choice questions on the online lectures. The quiz is administered and auto-graded online through the Learning Management System (LMS). It is made available only for the first 2 minutes of the class time. This activity not only motivates students to watch the lectures before class, but requires them to come to class to take the quiz and receive credit for it. It is important to note that the quiz questions are not integrated into the LMS (only the option to enter responses is set up online). The questions are revealed separately as a slide at the start of the class. Setting up 
this activity takes significant effort from the instructor, but once set-up, it works well and also allows for re-use of questions for future course offerings.

2) Review of online lectures (typically 5 minutes): After the short quiz, we dedicate few minutes to discuss questions from the quiz and online lectures. This provides an opportunity for students to ask questions on concepts that were unclear or difficult to understand, and helps the instructor identify parts of the online lectures that could be potentially improved.

3) Group problem-solving: (70-75 minutes): The majority of the classroom is then devoted to problem-solving as a group.

- Classroom setting: The classroom environment was also restructured to create a setting that is conducive from group problem-solving. Students were divided into groups of three. Each group was given a workspace and a white board to solve problems (see Figure 1). This allowed instructors to observe students' thought process, assist them as needed, and keep track of their progress during the class time. Oftentimes, when multiple students or groups had difficulty understanding a certain problem or concept, the instructor gathered those students as a bigger group for further explanation. Students took snapshots of their solutions or documented them electronically or on paper.
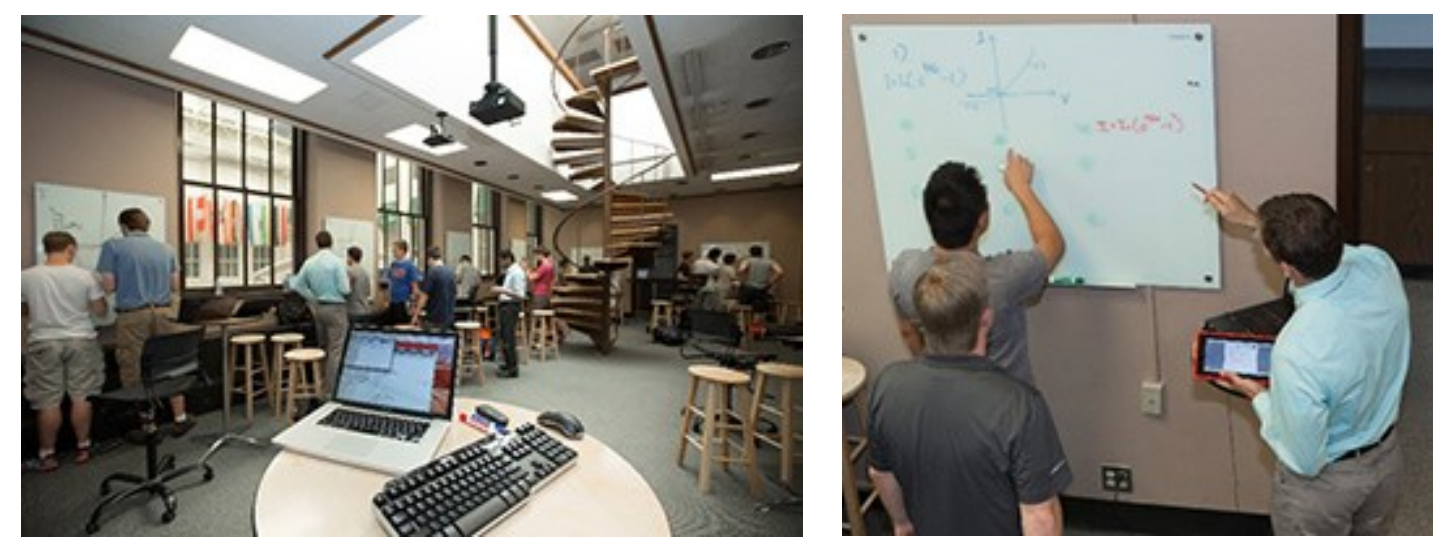

Figure 1: (Left) Renovated Flipped Classroom; (Right) Instructor reviewing problems with a student group (Photo Courtesy of the University of Cincinnati)

- In-class worksheets: A typical worksheet starts with simple problems or short questions to reinforce basic concepts and ends with challenging/open-ended questions. A sample worksheet is provided as an addendum. The worksheets were not developed from textbook questions or problems that are just "plug-and-chug". We custom-developed problems and questions that, (1) immediately reinforce key points learned from video lectures, (2) require true comprehension and group discussion, and (3) focus on difficulties and misconceptions that students encounter, and allow the instructor to closely observe and assist as needed. Each worksheet also includes few extra questions that students can continue to solve in class or on their own later. Worksheets are 
submitted online before the start of next class period, are graded for completion only, and solutions are posted shortly after that.

\section{Student Assessment and Tests}

Both in-class and out-class activities are, in effect, assessed through the quiz and worksheets, but these summative evaluations are given relatively lesser weights in the course grading system ( $20 \%$ for daily quizzes and $10 \%$ for completion of in-class worksheets; both are auto-graded). Student learning is primarily assessed through four objective exams that count for $70 \%$ of the course grade ( $15 \%$ for each of the first three exams and $25 \%$ for the last exam). An exam is scheduled after completion of each broad topic (diodes, BJTs, MOSFETs, and optoelectronics), and are comprehensive up to that point. Providing multiple tests lowers the stakes and allows students to focus on learning.

\section{Preliminary Results}

In the most recent offering of this class (Fall 2014), 18 electrical engineering students (18 male, 0 female) were enrolled. We present qualitative results to highlight the efficacy and limitations of the flipped pedagogy.

- Access to course material: Students found it very useful to be able to watch the videos at their own pace, and to have pre-recorded lectures readily available to them at all times during the course. On the other hand, it requires some self-regulation from the students to watch the assigned videos prior to class and be prepared to participate in in-class activities.

\section{Related excerpts from student feedback:}

1. "Personally, the best thing about the course is all the material you have to learn from. For once I can honestly say that we always had material to study with. With the videos, homework [solutions to in-class work], and the past exams, I feel like I was always able to go back and look at material I didn't understand. This made it easier to comprehend the material ... If every class had this much material given to us to use, it would be impossible to not learn."

2. ...It was nice being able to stop the videos and go back a bit if something wasn't quite understood. The one problem with this method is that $\mathbf{I}$ think it takes more selfcontrol to sit down and watch them before each class period. I feel like I learned more of the total content in this class than I have in almost any of my other college courses."

- In-class active learning: Modeled around learner-centered instruction, the flipped format resolves challenges with learning conceptually hard topics in semiconductor devices (and perhaps in other core electrical engineering courses as well), but it is no replacement for repetition of key calculations that must be preserved in learning activities. 


\section{Related excerpts from student feedback:}

1. "Most of the band diagram concepts would have been difficult to grasp in a traditional lecture. It seemed like the video lectures helped, but actually drawing them out in class under different conditions (positive voltage applied to one side, currents in different locations, etc) really helped solidify the concepts."

2. "Anytime the videos introduced a new equation to use... using it in class and breaking down each component helped clarify the most."

\section{Excerpt from instructor's own reflection:}

3. "For this first time, I did not have a single student visit during my office hours. [I believe] they were actually learning, and had all their questions answered during class... I felt like I was tutoring the entire class."

- Accommodating different learning styles: Based on the Index of Learning Styles (ILS) questionnaire $^{8}, 12$ students $(66.7 \%)$ self-reported as active learners and six students $(33.3 \%)$ reported as reflective learners. With clear and carefully-designed in-class and out-of-class worksheets, the majority of the students will adapt to the flipped format easily. There was at least one student who initially preferred traditional interactive lectures, but became more accepting few weeks into the semester.

\section{Related excerpts from student feedback:}

1. "I'm a very visual learner so being able to draw out diagrams many times with other people on a whiteboard was really helpful in cementing my understanding of semiconductors."

2. "I typically have a more passive learning style, but working in groups allowed me to be engaged in problems without being put on the spot to answer questions.

- Learning Communities: We mandated a weekly group change policy that there should be one new face in each group that they have not had for the past three weeks. The group problem-solving creates a sense of learning community ${ }^{9}$ among students, and helps them see that there is a group (community) that they can learn from and learn with.

\section{Related excerpts from student feedback:}

1. "While I could do this [working in groups] ... in a normal lecture style class, it would require that I find a group of people to work with outside of class for every single homework. I really liked doing homework on whiteboards with other students."

2 "Sometimes it was a little tiring having to work with other students who weren't paying as much attention."

3 "I really liked working in teams because since there is only 1 professor and way more students... the professor can't be at your side all class... so being with other people, we were able to help each other out in the sections that we were unsure of and also if none of us knew what to do for a certain problem we were able to put our minds together to solve the problems." 
While our study does not include comparisons to student performance in traditional lecture format, there is evidence in the research literature that students in a flipped classroom performed as well or better than students in comparable traditional lecture-style classroom ${ }^{10}$.

\section{Discussion}

Pros: In addition to several benefits highlighted in Section 4 and those observed by other practitioners ${ }^{11,12}$, the two truly beneficial aspects of the flipped pedagogy are: (1) The in-class activities and problems can be more real-world and open-ended, and the instructor can act as the "customer" and (2) It allows for a more inclusive instruction by potentially breaking down cultural and gender barriers and promoting communication between individual and groups of students. This is going to be increasingly important, given the changing demographics in engineering classrooms.

Cons: In the spectrum of Blended Learning (BL) course delivery modalities ${ }^{3}$, the flipped classroom model is more than replacing or supplementing F2F interactions with online components ${ }^{13}$. If not implemented strategically, the flipped format may negatively impact student learning as well as result in additional instructional preparation. Initially, it does take a lot of effort and time from the instructor to setup a flipped course, but once set-up correctly both instructors and students will start to see significant benefits. We recommend that instructors start by consulting the research literature and discussing strategies with early adopters within their institution. Another potential pitfall is that the flipped format may not be ideal for all engineering courses. For example, advanced courses that are either project-based or research-based may not be suitable candidates for complete inversion, but may fit into other BL course delivery modalities.

\section{Creating Awareness of Blended Learning at Institution-level}

An important first step towards institutionalizing BL strategies is exploration and awareness, where individual faculty members explore, implement, and advocate specific BL benefits ${ }^{3}$. Since there are no identified processes or faculty incentives at this stage, it is often a challenge for instructors to communicate their new pedagogical methods to the university community at large. To this end, we undertook several outreach activities at the department-, college-, and universitylevel, and the following is a summary of our efforts:

Official Press Release: One of most impactful ways to publicize instructional endeavors is to run a news article through the institution's office of communications. In collaboration with our department faculty and other early adopters of the blended learning, the university news media featured our course in an article on flipped classrooms ${ }^{14}$. This resulted in not only widespread awareness of the topic among faculty, students, and administrators, but also increased focus on technological support for flipped, blended, and online classrooms. 
Workshops and Seminars: We also participated in formal workshops and brown-bag conversations at the college-level to share our experiences as well as foster discussions on innovative teaching practices. Such conversations allowed for engineering faculty and students to hear about teaching excellence outside of their departments and gather effective BL guidelines that may be applicable to their own courses.

Advocacy at Department-level: This work was formally presented in our department's annual Industry Advisory Board meeting and informally, in several departmental faculty meetings. The course evaluation results are a testimony of student learning in a flipped classroom and therefore, we actively share and discuss the evaluation results with interested faculty.

In addition to initiating and coordinating the press release, several engineering faculty (including the instructor of EECE 2077) participated and contributed to all of the above dissemination channels.

\section{Conclusion}

In summary, an inverted (flipped) classroom model was successfully applied to an undergraduate electrical engineering course. Several core courses in the electrical and computer engineering curriculum, including our first-year introductory Engineering Models courses, are also being offered in the flipped format ${ }^{15}$. We anticipate that this case study will be particularly useful for first time course developers and/or instructors interested in migrating to the flipped classroom style, and our outreach efforts will encourage administrators to increase focus on defining and regulating BL models at their own institutions.

Addendum: Sample In-class Worksheet

\section{Topic: Contact Potential}

\section{In-Class Problems}

1. Draw the two blocks of semiconductor shown below (you don't need to draw all the charges inside, just 1 colored rectangle for each block. Draw it WIDE and higher up on the board, as you will need to draw underneath it too.

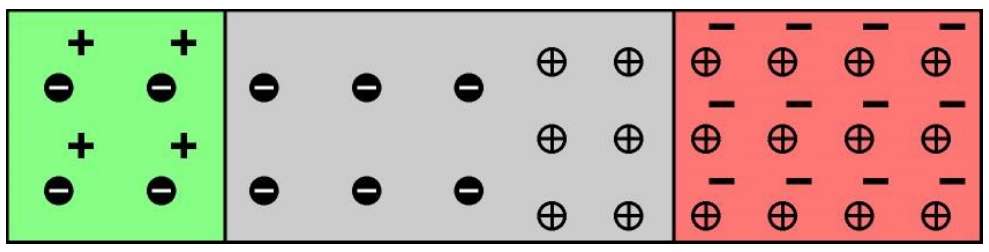


a. Label where the two blocks were joined with a black vertical line.

b. Label each block as either: 'Phosphorus atoms and free carriers '/ 'Boron atoms and free carriers' / 'Boron atoms only' / 'Phosphorous atoms only'

c. Label locations where you get 'maximum E-field' and 'zero E-field' and make sure you understand why.

d. Draw a band-diagram underneath this, extending vertical dotted lines down for the edges of the depletion region, and extending down the vertical line for where the blocks were, such that they all go through your band-diagram. Label Ec/Ev/Ef on the diagram. Make sure EVERYTHING in the diagram represents un-equal dopings, including the Fermi-level distances from the bands.

2. E-field causes band diagrams to have slope! Anytime you have E-field, you know it means the bands must bend! Redraw each E-field plot on the board, and below the E-field plots draw the corresponding band diagrams (don't worry about the Ef or dopings, just plot the conduction and valence bands). To help solve this problem, use the electrons=water and holes=bubbles analogy and think how they each should move (left or right) in the E-field. Assume the E-field is measured in the direction from left to right. Remember, higher E-field should make the bands slope steeper! (postive E-field = positive bands slope / negative Efield $=$ negative bands slope).

3. Questions related to potential across a diode...

a. Calculate the total amount of band-bending (energy, E) that would be achieved for a $\mathrm{PN}$ junction, in units of eV, for a diode that is doped $10^{17} / \mathrm{cc} \mathrm{p}$-type and $10^{15} / \mathrm{cc}$ n-type. Hint, calculate for volts, then change it to units of $\mathrm{eV}$. Is simple, for example $1 \mathrm{~V}$ will turn into $1 \mathrm{eV}$. Another hint, at $300 \mathrm{~K}$ thermal voltage is always $0.0259 \mathrm{~V}$, so you don't need to calculate that part of the equation.

b. On what side would most of the most of the depletion width occur?

c. If $+0.3 \mathrm{~V}$ is added to the $\mathrm{n}$-side while the $\mathrm{p}$-side is grounded, what will be the new total amount of band-bending (in eV)? We have not done this in class, but just think about it... answer is simple (think how bands would bend).

d. A diode has internal contact potential. If you hooked a diode up w/ a wire loop to connect the $\mathrm{n}$ and $\mathrm{p}$-sides with the wire, would the internal voltage cause current to continue to flow through the wire?

4. Draw the band shown below and then: 


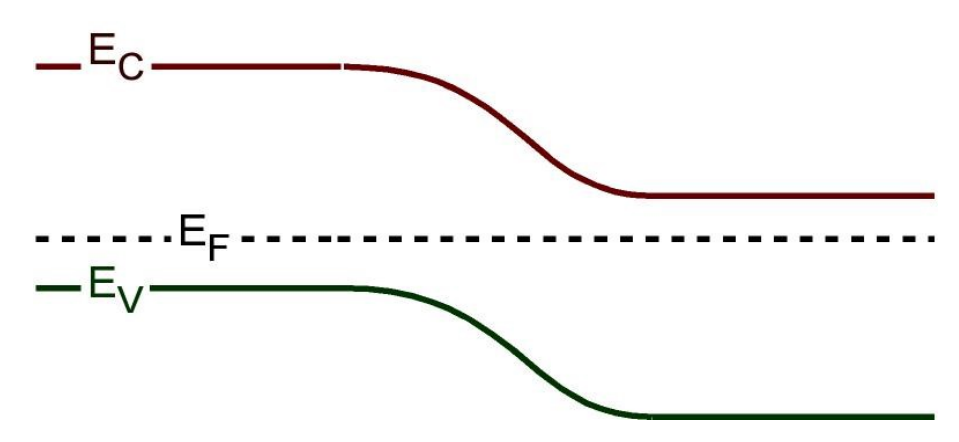

a. Add electrons and holes where you think they should be, and try to show the concentrations you expect (for example, maybe 10-12 carriers for majority carriers, and may only 2-3 for minority carriers).

b. Draw with a line-path and arrow-head at the end, the starting point, path, and destination for electron drift current.

c. Draw with a line-path and arrow-head at the end, the starting point, path, and destination for electron diffusion current

d. Draw with a line-path and arrow-head at the end, the starting point, path, and destination for hole drift current

e. Draw with a line-path and arrow-head at the end, the starting point, path, and destination for hole diffusion current

5. Last question, a repeat from last week because this is very important, again, figure out how a diode works on your own before I even teach you! A diode is rectifying, meaning it gives you very small (nearly zero) current in one direction (voltage polarity) and large current in the other direction (voltage polarity).

a. For the case of negative voltage applied to the $\mathrm{p}$-side and the n-side grounded, re-draw the conduction and valence bands (don't worry about drawing the Fermi level). Then draw and label the resulting current as dominated by drift or diffusion (only one will dominate) and if it is large or small (think of number of carriers feeding the resulting current, are they majority or minority carriers?).

b. For the case of positive voltage applied to the p-side and the n-side grounded, re-draw the conduction and valence bands (don't worry about drawing the Fermi level). Then draw and label the resulting current as dominated by drift or diffusion (only one will dominate) and if it is large or small (think of number of carriers feeding the resulting current, are they majority or minority carriers?).

Extra Problems (if you have time, finish during class when I can help, or on your own time

6. The drift current for a diode at thermal equilibrium originates from (choose one of the following):

a. _ minority carriers that are thermally generated NEAR the depletion region edge and 
swept across by E-field

b. _ majority carriers that are thermally generated NEAR the depletion region edge and swept across by E-field

c. _ minority carriers that are from dopants NEAR the depletion region edge and swept across by E-field

d. _ majority carriers that are from dopants NEAR the depletion region edge and swept across by E-field

7. Some review... A slab of semiconductor with a mobility of $1000(\mathrm{~cm} / \mathrm{s}) /(\mathrm{V} / \mathrm{cm})$ or $\mathrm{cm}^{2} / \mathrm{V}-\mathrm{s}$, is setup at steady state to have electrons injected at one side and removed from the other side such that on one side there are $10^{17}$ electrons and on the other side there are $10^{7}$ electrons. Assume the semiconductor slab is $0.01 \mathrm{~cm}$ long $(100 \mu \mathrm{m})$. Calculate the resulting diffusion current density $\left(\mathrm{A} / \mathrm{cm}^{2}\right)$. Reminder, thermal voltage is $0.0259 \mathrm{~V}$ at $300 \mathrm{~K}$.

8. Some more review. Drift and diffusion currents! Example equations below are for n-type semiconductor.

$$
\begin{aligned}
J_{n}(\text { drift }) & =q \mu_{n} n(x) \mathrm{E}(x) & & J_{n}(\text { diffusion })=q D_{n} \frac{d n(x)}{d x} \\
& =q \frac{(\mathrm{cm} / \mathrm{s})}{(V / \mathrm{cm})}\left(1 / \mathrm{cm}^{3}\right)(V / \mathrm{cm}) & =q\left(\mathrm{~cm}^{2} / \mathrm{s}\right)\left(1 / \mathrm{cm}^{4}\right) & D_{n}=\mu_{n} k T / q
\end{aligned}
$$

a. Which type of current requires that the particles have charge in order to move? _ drift. _ diffusion. _ both. _ neither.

b. Which type of current requires a concentration gradient of the particle distribution in order to move? _ drift. _ diffusion. _ both. _ neither.

c. Why do we have a ' $q$ ' in the front of both equations? One sentence max.

d. What is mobility, basically? One sentence max. Look at the units to create your definition!

e. For diffusion coefficient $D_{n}=\mu_{n} k T / q$, why do we need the kT/q? One sentence max.

f. If you create an excess of electrons at some point (delta function) in a slab of semiconductor material they will diffuse away, what concentration profile (equation) mathematically represents the excess carrier concentration as a function of distance? 


\section{References:}

1. Graham CR. Blended learning systems. CJ Bonk \& CR Graham, The handbook of blended learning: Global perspectives, local designs.Pfeiffer. 2006.

2. Bonk CJ, Graham CR. The handbook of blended learning: Global perspectives, local designs. John Wiley \& Sons; 2012.

3. Graham CR, Woodfield W, Harrison JB. A framework for institutional adoption and implementation of blended learning in higher education. The internet and higher education. 2013;18:4-14.

4. Fulton K. Upside down and inside out: Flip your classroom to improve student learning. Learning \& Leading with Technology. 2012;39(8):12-17.

5. Hughes H. Introduction to flipping the college classroom. . 2012;2012(1):2434-2438.

6. Herreid CF, Schiller NA. Case studies and the flipped classroom. Journal of College Science Teaching. 2013;42(5):62-66.

7. Bishop JL, Verleger MA. The flipped classroom: A survey of the research. . 2013.

8. Felder RM, Spurlin J. Applications, reliability and validity of the index of learning styles. International journal of engineering education. 2005;21(1):103-112.

9. Benkler Y, Nissenbaum H. Commons- based peer production and virtue*. Journal of Political Philosophy. 2006;14(4):394-419.

10. Mason GS, Shuman TR, Cook KE. Comparing the effectiveness of an inverted classroom to a traditional classroom in an upper-division engineering course. Education, IEEE Transactions on. 2013;56(4):430-435.

11. Kim MK, Kim SM, Khera O, Getman J. The experience of three flipped classrooms in an urban university: An exploration of design principles. The Internet and Higher Education. 2014;22:37-50.

12. Mason G, Shuman TR, Cook KE. Inverting (flipping) classrooms-Advantages and challenges. . 2013.

13. Strayer JF. How learning in an inverted classroom influences cooperation, innovation and task orientation. Learning Environments Research. 2012;15(2):171-193.

14. University of Cincinnati News. UC professors 'flip' the lectures. http://www.uc.edu/news/NR.aspx?id=20534. Updated 2014.

15. Ossman KA, Bucks GW. Effect of flipping the classroom on student performance in first-year engineering courses. . 2014. 